\title{
The capability enhancement of aluminium casting process by application of the novel CRIMSON method
}

\author{
Xiaojun Dai ${ }^{1}$, Mark Jolly ${ }^{2}$, Binxu Zeng ${ }^{3}$ \\ ${ }^{1,2,3}$ School of Mechanical Engineering, University of Birmingham, Edgbaston, Birmingham, \\ B15 2TT, UK
}

Key words: aluminium casting process, CRIMSON, melting, oxide film,

\begin{abstract}
The conventional foundry not only frequently uses batch melting, where the aluminium alloys are melted and held in a furnace for long time, sometimes as long as a complete shift, but also uses the gravity sand casting process where the molten aluminium alloys are transferred using a ladle from furnace to pour station and are poured into a mould. During the filling of the mould, the turbulent nature of the liquid metal gives rise to massive entrainment of the surface oxide films which are the subsequently trapped into the liquid and act as micro cracks. Also the long exposure time of the liquid surface to the surrounding environment during melting, transferring and filling will increase the level of hydrogen absorption from the atmosphere. The abovementioned factors are often the main reasons for casting defect generation. In this paper the novel CRIMSON aluminium casting method is introduced which has a number of advantages. Instead of gravity filling method, it uses the single shot upcasting method to realize the rapid melting and rapid counter-gravity-filling mould operations which reduce the contact time between the melt and environment thus reducing the possibility of defect generation. Another advantage is the drastic reduction of energy consumption due to shortened melting and filling time. A simulation software, FLOW-3D, is used to compare this new method with the conventional gravity casting process. A tensile bar case is used as a sample to simulate the filling process.
\end{abstract}

\section{Introduction}

The casting industry has been driven by the requirement of improving product quality and minimisation of the production costs. To satisfy these requirements both casting production process and energy efficiency play vital roles in the foundry. In addition to the pressure of rising energy price and the limitation of strict environment protection legislation it is confirmed that under the right socioeconomic conditions efficiency optimisation of industrial process can be an important step toward increased industrial sustainability [1]. Selection of the proper casting process, facility and minimisation of the energy consumption will be the key factors for the casting enterprise to successfully compete against rivals in the tough market.

In conventional foundries, the capacity of a typical aluminium alloy melt furnace usually is between the range of $100 \mathrm{~kg}$ and several tonnes. The liquid metal is held at about $700{ }^{\circ} \mathrm{C}$ in a holding furnace before it is transferred to a ladle and poured into a casting mould at pour 
station. It can take several hours, or even several days, for the liquid metal in a batch to be used up and any leftover metal is poured off to be re-used or scrapped for re-melting or refining in a secondary processing plant [2].

Quality issues can arise when the liquid metal reacts with hydrogen, oxygen and water in the atmosphere. An oxide surface layer is created when the melted aluminium alloy is exposed to the air. During filling a casting mould the turbulent filling behaviour of the liquid metal due to gravity is easy to make the oxide films on the surface of the liquid cracked and trapped into the liquid. Also the long exposing time of the liquid surface with the around air during melting, transferring and filling will increase the thickness of the oxide film on the liquid surface and the level of hydrogen absorption. All of these will result in layers of cracked oxide films, porosity and shrinkage which damage the integration of the micro-structure of the alloy, leading to degraded mechanical properties of the end product $[3,4]$.

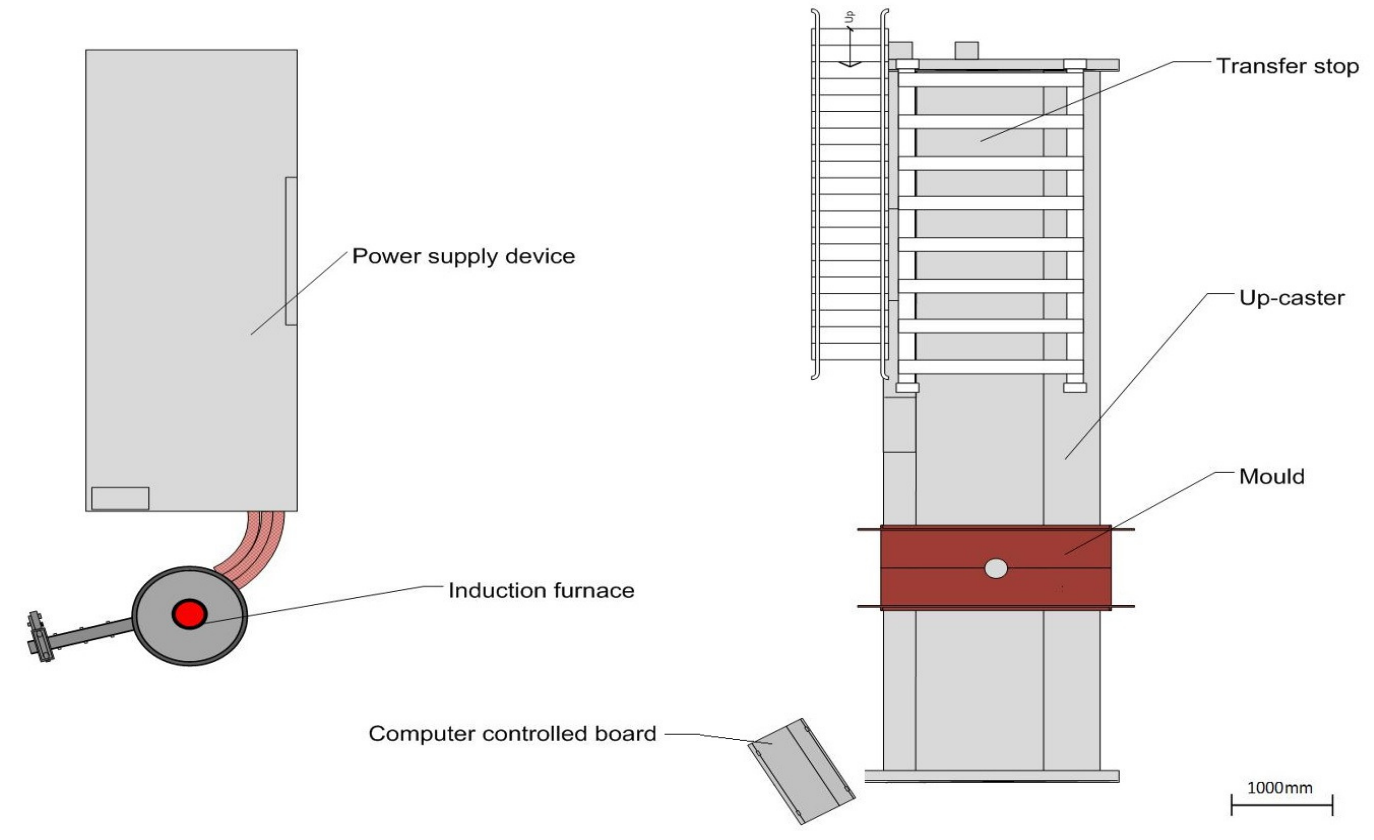

Figure 1 Schematic plan of the new casting process facility

A new CRIMSON (Constrained Rapid Induction Melting Single Shot Up-Casting) method has been co-invented by the researchers of University of Birmingham and engineers from a local company, N-Tec LTD. The aims to develop this new method are to reduce the energy consumption and to improve the casting quality within light-metal casting industry. The methodology of the new method is to melt enough quantity of alloy in a closed crucible of an induction furnace to fill a single mould and avoid unnecessary energy consumption. The layout of the CRIMSON facility is shown in Figure 1. The new process features quick melting, quick filling and minimising holding time which reduces the opportunity of hydrogen absorption and generation of surface oxide film [5].

In this paper, the tensile test bar is used as a sample and a CFD simulation software (Flow-3D) is used to simulate the casting process of filling a casting mould. Sand moulds for the new up-casting method and conventional gravity sand casting are designed to compare their filling behaviours using the numerical simulation method. In addition the traditional melting process 
from one local company is investigated and it is compared with the new up-casting method. We mainly focus on the issues of quality and energy saving, other issues will be investigated later in our research project. The simulation results for filling the sand moulds of two different casting processes are compared to see how the new method can avoid the turbulent behaviour of liquid metal flow during filling a mould. The calculation and analysis of energy consumption are completed to see what the difference between the current melting processes and the novel method. Thus, the quality issue and the potential energy saving for the new method can be found. This comparison is only one of a number being carried out under the support of an EPRSC project where four conventional casting processes will be benchmarked for their scrap rates and energy usage.

\section{Runner system design and simulation software}

Runner system design of CRIMSON method and gravity sand casting method

A runner system for CRIMSON method is shown in Figure 2(a) where the system consists of runner, ingate, riser, feeder and six tensile bars. A runner system of gravity sand casting is shown in Figure 2(b) where the system consists of basin, down sprue, runner, ingate, riser, feeder and six tensile bars.

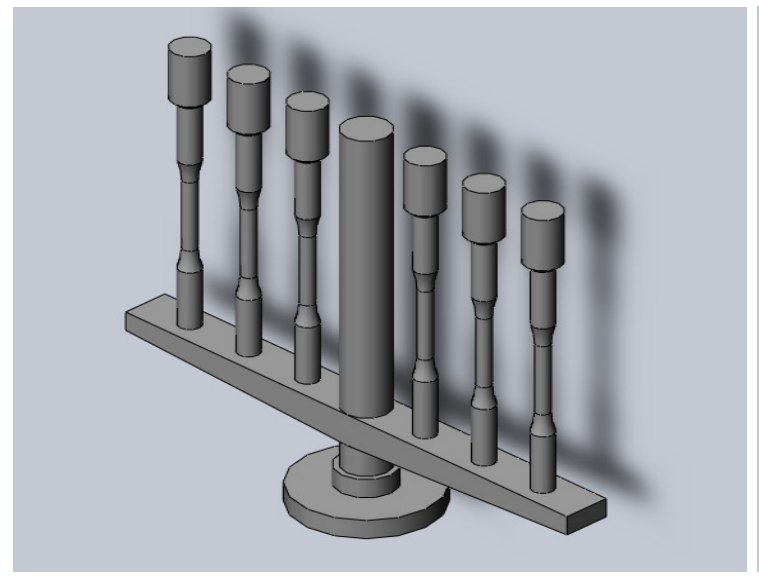

(a) CRIMSON

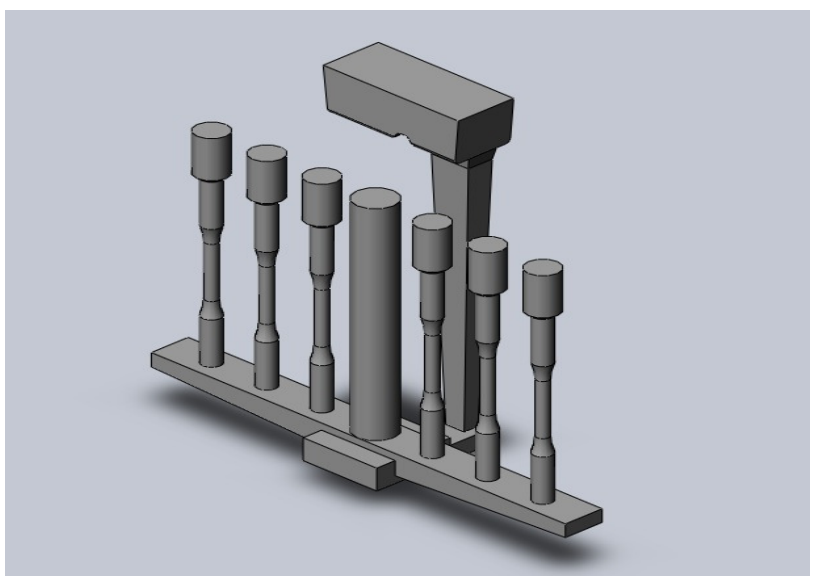

(b) Gravity sand casting

Figure 2 Structure of the tensile bar with different runner systems.

Simulation software and conditions

In order to simulate the liquid metal flow in different runner systems, a commercial Flow-3D CFD simulation software is used. A 'velocity magnitude' method of the Flow-3D code is used to predict the flow behaviour of liquid metal during filling a mould. The simulation is implemented using a Workstation with 16.00GB RAM and eight 2.66GHz CPUs.

For the simulation of the CRIMSON runner system, Finite Difference Method (FDM) is used to generate the mesh which includes about 170,000 control volumes (cells). The filling flow rate of $0.25 \mathrm{~L} . \mathrm{s}^{-1}[6]$ and a pressure of $9 \mathrm{kPa}$ were used. For the runner system of gravity sand casting, the mesh has about 240,000 control volumes (cells). Same main conditions for the simulation of both runner systems are: pouring temperature is $700{ }^{\circ} \mathrm{C}$ and the around atmosphere pressure is $1 \mathrm{~atm}\left(1.013 \times 10^{5} \mathrm{kPa}\right)$. 


\section{Test facilities and casting sample for energy saving}

\section{Test facilities}

CRIMSON facility: the layout and main components of the new facility is described in Figure 1.Where its main components are: Induction furnace $(275 \mathrm{KW})$, power supply device, up-caster, computer-controlled board and mould transfer stop.

Melting facility of $G \& W$ LTD: Grainger \& Worrall $(\mathrm{G} \& \mathrm{~W})$ LTD is using a melting furnace with a capacity of 4 tonne (Figure 3 ) where the gas is used to preheat and melt aluminium ingot and the electricity is used to adjust the melted liquid alloy to a required overheating temperature. The holding time for the furnace is up to 4-5 days. For A354 aluminium alloy the overheating temperature is $760{ }^{\circ} \mathrm{C}$ and the pouring temperature is $700{ }^{\circ} \mathrm{C}$.

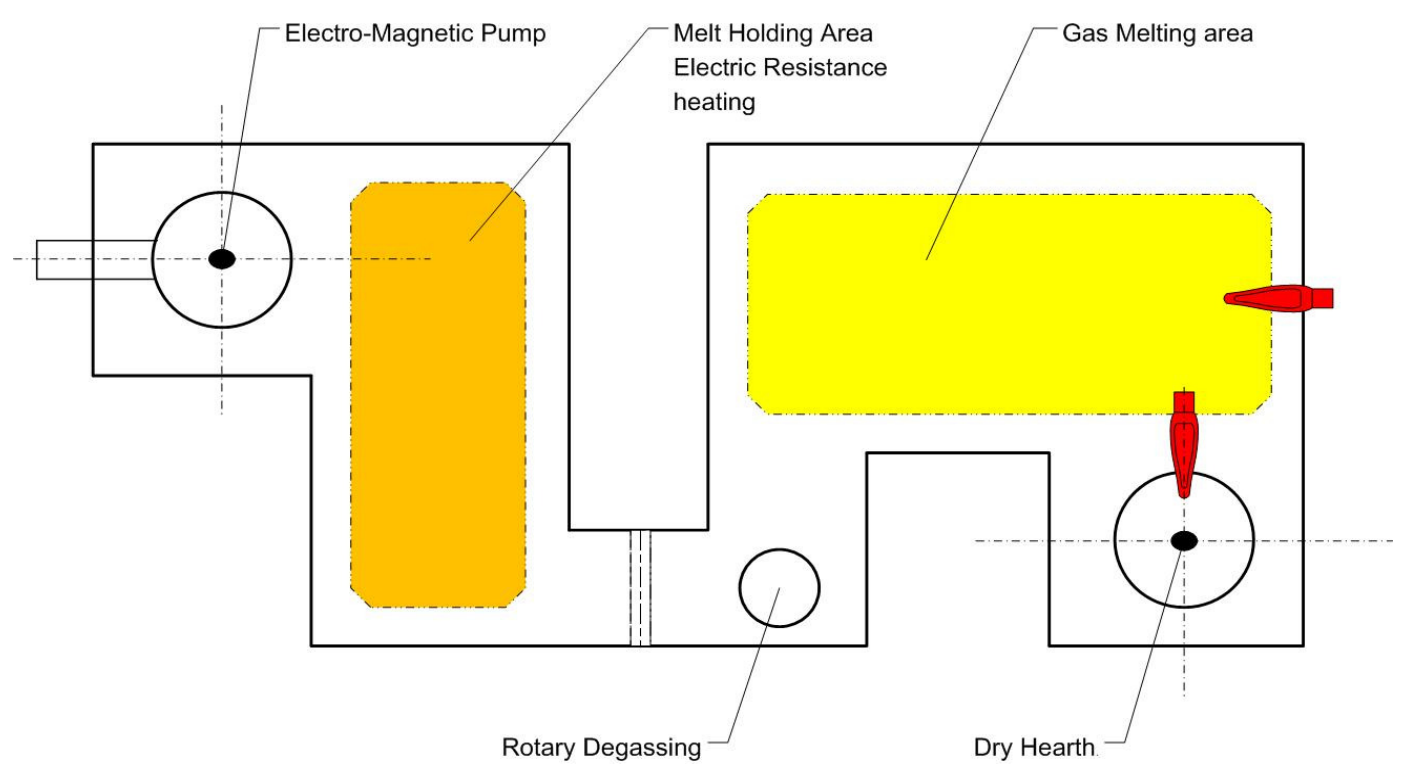

Figure 3 Schematic of the aluminium melting furnace in G\&W LTD.

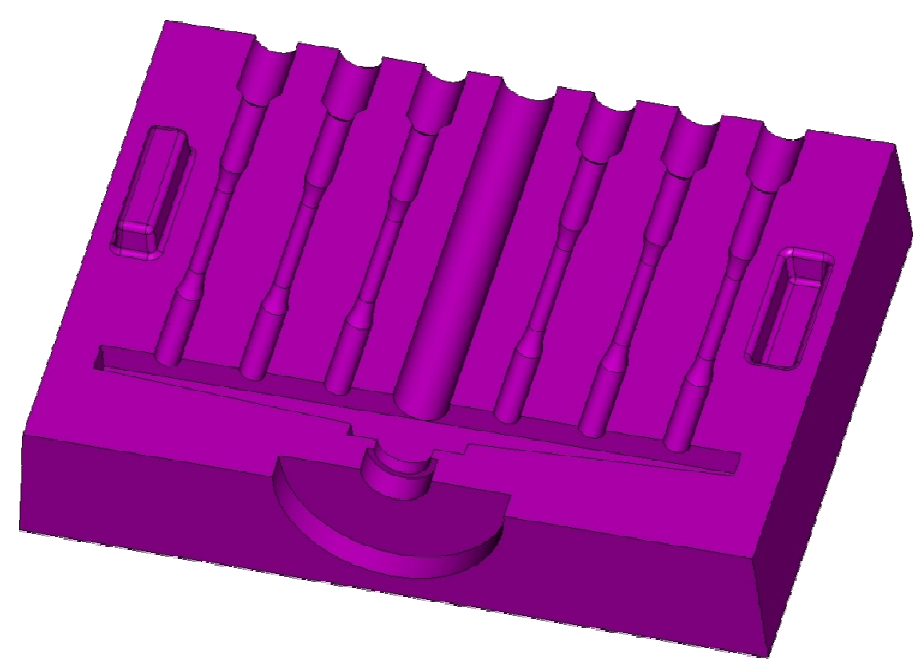

Figure 4 Sand mould of the tensile bar 
Casting sample and mould selected for comparing the energy consumption

Half of sand mould of the tensile bar is shown in Figure 4 which has also been selected to use novel method and conventional casting process from G\&W to examine the difference of energy consumption. The mould with a runner system has a profile of $530 \mathrm{~mm}$ length $\mathrm{x}$ $390 \mathrm{~mm}$ width x $100 \mathrm{~mm}$ height and has a weight of $4 \mathrm{~kg}$ for filling metal [7].

\section{$\underline{\text { Simulation }}$}

\section{Results and discussion}

For the simulation of runner system of CRIMSON method, the filling time is 6.08 seconds. The simulation took about 30 minutes. The velocity magnitude of the liquid metal during filling is depicted in Figure 5 where the filling velocity of liquid metal can be observed using the velocity scale.

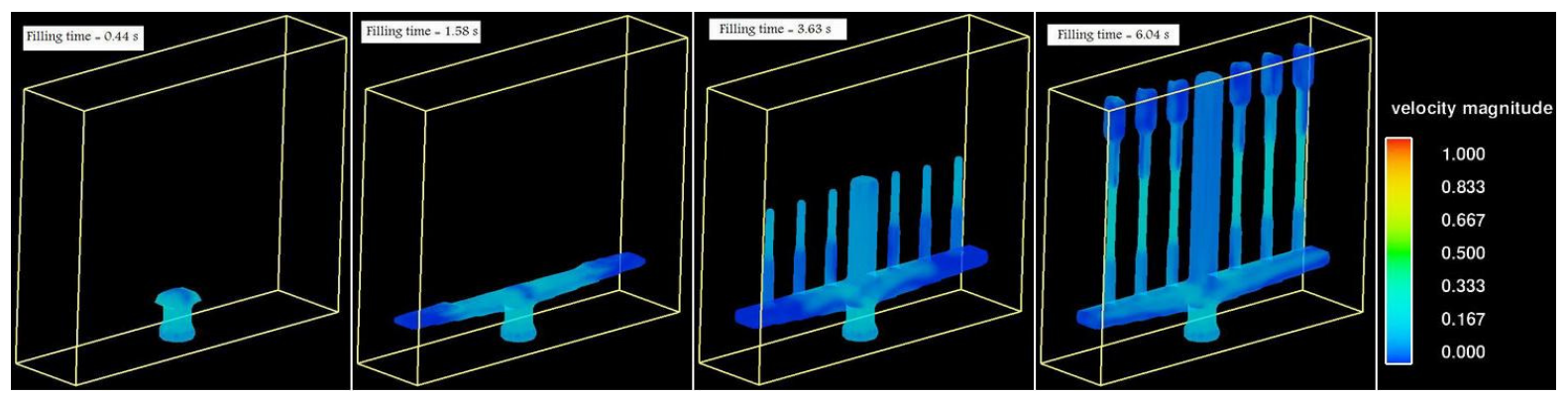

Figure 5 Numerical simulation of runner system of CRIMSON method.

For the simulation of runner system of gravity sand casting, the filling time is 3.67 seconds. The simulation took about 20 minutes. The velocity magnitude of the liquid metal during filling a mould is described in Figure 6 where the velocity of liquid flow can be judged using the velocity scale.

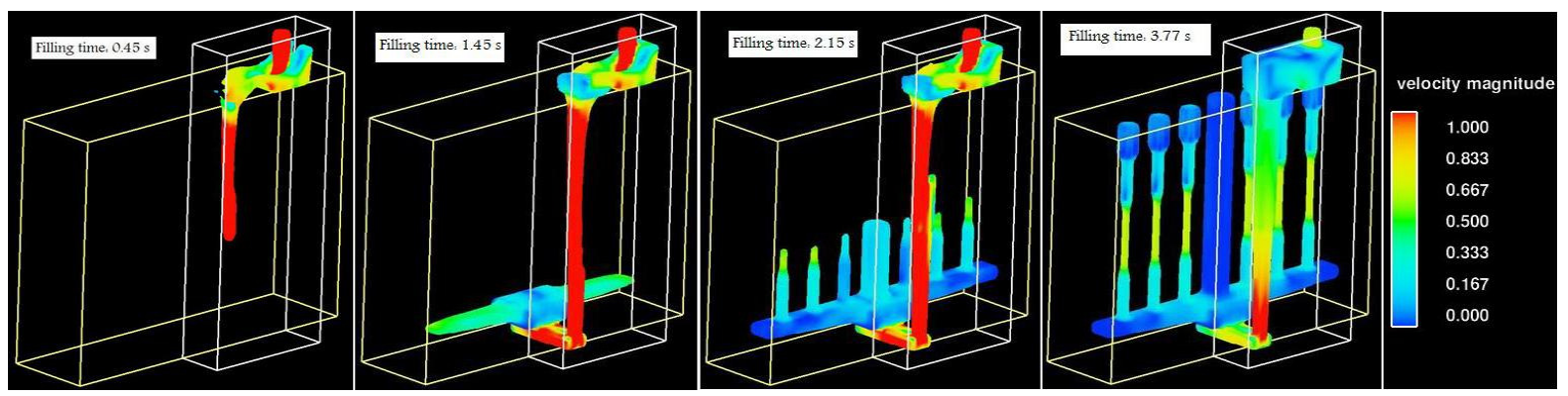

Figure 6 Numerical simulation of runner system of gravity sand casting.

From Figure 5, it is found that the maximum velocity of liquid metal flow during filling is $0.4 \mathrm{~m} . \mathrm{s}^{-1}$ which is less than $0.5 \mathrm{~m} . \mathrm{s}^{-1}$. The quiet flow behaviour of liquid metal in the runner system during filling was approved proper for avoiding the generation of trapped oxide films, porosity and other casting defects [8]. In addition the filling method using against gravity decreases the exposing time to the air which will reduce the opportunity of generating oxide films. 
From Figure 6, the maximum velocities of liquid metal flow in downsprue and in runner during filling are more than $1.0 \mathrm{~m} . \mathrm{s}^{-1}$, respectively. These phenomena mean that the violent and turbulent follow flow behaviour will easily to crack the oxide films on the liquid and make them trapped into the liquid. Although the filter existed in the runner system can leach the coarse trapped oxide films from the liquid which depends on the size of the holes and effectiveness of the filter, the fine oxide films will still pass through the filter and remain in the liquid. After solidification, these remained fine oxide films will generate the defects such as porosity, shrinkage etc [3,4]. In the mean time, the turbulent flow behaviour of liquid metal in the downsprue and runner will readily make the air or hydrogen entrapped into the liquid where the porosity or bubble will be formed which will impair the mechanical properties of the casting [9]. In addition the long transferring time from furnace to ladle and the usage of the traditional gravity filling method make the melted liquid metal exposed to the air for long time, which increases the opportunity of generating oxide films on the surface of the liquid metal.

Based on the abovementioned discussion, it is found that the up-casting filling process that the new method used can drastically reduce the opportunity of generating oxide film on the surface of the liquid alloy and the potential time for hydrogen absorption. Therefore, the quality of the casting can be secured accordingly. In opposition to the new process, the filling process of the conventional gravity sand casting process has the violent flow behaviour which will easily make the oxide films on the liquid metal and the air entrapped into the liquid which will generate different type of casting defects and damage the mechanical properties of casting.

\section{Energy saving}

The energy consumption of the two types of melting processes was investigated and the results and the calculated energy efficiency were recorded in Table 1.

\begin{tabular}{|l|l|l|l|}
\hline Melting process & Energy consumption & Energy efficiency & $\begin{array}{l}\text { Normal energy } \\
\text { efficiency of furnace }\end{array}$ \\
\hline $\begin{array}{l}\text { G\&W } \\
(\text { Gas+Ele })\end{array}$ & $\begin{array}{l}27.86 \mathrm{MJ} \cdot \mathrm{kg}^{-1} \\
\left(\text { Gas: } 17.78 \mathrm{MJ} \cdot \mathrm{kg}^{-1}\right. \\
\left.\text { Ele: } 10.08 \mathrm{MJ} \cdot \mathrm{kg}^{-1}\right)\end{array}$ & $\begin{array}{l}\text { Gas: } 5.65 \% \\
\text { Ele: } 1.70 \%\end{array}$ & $\begin{array}{l}\text { Gas: } 7 \sim 19 \% \\
\text { Ele: } 59 \sim 76 \%\end{array}$ \\
\hline $\begin{array}{l}\text { CRIMSON } \\
\text { Induction furnace }\end{array}$ & $1.98 \mathrm{MJ} \cdot \mathrm{kg}^{-1}$ & $57.82 \%$ & Ele: $59 \sim 76 \%$ \\
\hline
\end{tabular}

Table 1 Energy consumption and energy efficiency of the two different melting facilities

As shown in Table 1, the thermal efficiency of the melt furnace at G\&W for gas is $5.65 \%$ and for electricity is $1.70 \%$. The former $5.65 \%$ is close to the normal thermal efficiency of crucible furnace using gas (7 19\%). There is a big difference between the later $(1.70 \%)$ with the normal value (59 76\%) which shows that the current melting process consumes much more electricity or energy at G\&W due to the long holding time. Therefore, if the current long holding process at G\&W is replaced by the new method, 14 times more energy could be saved. It is estimated that when using the new process $25.88 \mathrm{GJ}^{-t_{0}} \mathrm{tone}^{-1}\left(7.19 \mathrm{MWh}^{- \text {tonne }^{-1}}\right)$ 
of energy could be saved for producing A354 casting alloys and thus the melting cost will be significantly reduced.

\section{Conclusions and future works}

From the simulation results, the maximum flow velocity of the new CRIMSON method during filling a mould is less than $0.5 \mathrm{~m} . \mathrm{s}^{-1}$. The total flow behaviour is quiet and stable which avoids the possibility of generation of oxide films and other casting defects. In opposition to the new method, the conventional gravity sand casting process has turbulent flow behaviour during filling a casting mould where the maximum velocities of liquid flow in the downsprue and runner are more than $1.0 \mathrm{~m} . \mathrm{s}^{-1}$. The violent flow behaviour will not only easily make the oxide films on the liquid metal cracked and entrapped into the liquid but also make the air trapped into the liquid. These entrapped oxide films and air will generate different types of casting defects such as porosity, shrinkage and bubble etc which will damage the mechanical properties of the final casting.

The investigation on energy consumption and the melting efficiency of both methods has showed that the new method is a novel method for reducing energy consumption. If the traditional melting process at G\&W could be replaced by the new melting method, the estimated energy savings could be of the order of 26 GJ.tonne- $^{1}\left(7.19 \mathrm{MWh}^{-t_{0}} \mathrm{e}^{-1}\right)$. The production cost could be reduced about $£ 546$ pounds.tonne ${ }^{-1}\left(7.6 \mathrm{p} . \mathrm{kWh}^{-1}\right)$.

To validate the simulation results, the experiment on comparing the mechanical properties of the tensile bar using different filling processes will be implemented in next stage. The other issues of the energy efficiency for the foundry will be considered too where not only the melting process is included, other relevant processes should be considered.

\section{Acknowledgement}

This research project is sponsored by the Engineering and Physical Sciences Research Council (EPSRC) of the UK under the grant of EP/G060096/1. Many thanks to the University of Birmingham, N-Tec LTD. and Grainger \& Worrall Ltd for providing the experiment equipment and data. 


\section{References}

[1] BSC, Incorporated, Advanced Melting Technologies: Energy Saving Concepts and Opportunities for the Metal Casting Industry, Report, U.S. Department of Energy, 2005.

[2] Casting method saves energy, 25, Mar 2009, Professional Engineering Magazine. http://www.profeng.com/archive/2009/2206/22060076.htm

[3] X. Dai, X. Yang, J. Campbell and J. Wood, 2003, Effects of runner system design on the mechanical strength of Al-7Si-Mg alloy castings, Journal of Materials Science and Engineering. A354. $\operatorname{Pg} 315-325$.

[4] X. Dai, X. Yang, J. Campbell \& J. Wood, "The Influence of Oxide Film Defects generated in Filling on the Mechanical Strength of Aluminium alloy Castings", Materials Science and Technology, 2004, 20(4), 505-513.

[5] M. Jolly, Energy Saving in the Foundry Industry by Using the "CRIMSON" Single Shot UPCasting Process, 2010 TMS Annual Meeting \& Exhibition, Febuary 14-18, 2010, Seattle, WA.

[6] J. C. Gebelin, M. Lovis \& M.R. Jolly, SIMULATION OF TENSILE TEST BARS: DOES THE FILLING METHOD MATTER?, Symposium on Simulation of Aluminum Shape Casting Processing, TMS2006 March 2006, Warrendale, PA, Eds Q. Wang, M.J.M Krane and P.D Lee.

[7] X. Dai, M. Jolly, Potential energy savings by application of the novel CRIMSON aluminium casting process, Applied Energy (Accepted for publication)

[8] J. Campbell, (1991) Casting, Butterworth-Heinemann, Oxford.

[9] M. Divandari, 2001, PhD Thesis, 'Mechanisms of bubble damage in castings'. University of Birmingham. 
The capability enhancement of aluminium casting process by application of the novel CRIMSON method

\author{
Dai, Xiaojun
}

Wiley

Xiaojun Dai, Mark Jolly and Binxu Zeng. The capability enhancement of aluminium casting process by application of the novel CRIMSON method. Shape casting: 4th international symposium 2011 in honor of Prof. John T. Berry. 27 February - 3 March 2011, San Diego, California. USA.

https://dspace.lib.cranfield.ac.uk/handle/1826/11454

Downloaded from Cranfield Library Services E-Repository 